\title{
Mapa do Valor Conservativo dos Hábitats Potenciais da Fauna Silvestre para o Município de São Gabriel, RS, Brasil
}

\author{
Map Conservative Value of Potential Habitats for the Municipality of São Gabriel, RS, Brazil
}

\author{
Tharso José Foletto Blasckesi, Rafael Cabral Cruz \\ Universidade Federal do Pampa - Campus São Gabriel, RS, Brasil \\ tharsofoletto@gmail.com rafaelcruz@unipampa.edu.br
}

\begin{abstract}
Resumo
As mais recentes estimativas da diversidade de espécies no planeta apontam a existência de 10 milhões de formas de vida, das quais apenas cerca de 1,7 milhões já estariam classificadas. As atividades antrópicas devem ser precedidas por um minucioso entendimento das variáveis ambientais e dos processos ecológicos, através dos diagnósticos adequados. Desta forma, o presente trabalho está relacionado com o geoprocessamento do mapa do valor conservativo dos hábitats potenciais da fauna silvestre para o município de São Gabriel, RS, Brasil. O objetivo é subsidiar informações para o processo de tomada de decisão para a conservação das espécies da fauna silvestre ameaçadas de extinção neste município. A metodologia de pesquisa envolveu a definição da área de abrangência, o levantamento das espécies, a definição dos critérios de seleção e o geoprocessamento dos mapas. A análise do mapa do valor conservativo permitiu interpretar e classificar, no município de São Gabriel, as áreas de acordo com um gradiente de valor conservativo. Também foi possível avaliar a distribuição dos grupos taxonômicos e as espécies que contribuíram para a formação do mapa do valor conservativo. Estas informações são um subsídio para o desenvolvimento de estratégias de gestão territorial conforme os conceitos de Gestão da Biodiversidade.
\end{abstract}

Palavras-chave: Valor conservativo. Conservação do hábitat. Biodiversidade.

\begin{abstract}
The latest estimates of species on the planet diversity point to the existence of 10 million life forms, of which only about 1.7 million are already classified. Human activities must be preceded by a thorough understanding of environmental variables and ecological processes, through the correct diagnosis. Thus, the present work is related to the GIS map of the conservative value of the potential habitats of wildlife for the municipality of São Gabriel, $R S$, Brazil. The aim is to support information for the decision-making process for the conservation of wildlife species threatened with extinction in this municipality. The research methodology involved the definition of the area covered by the survey of the species, the definition of selection criteria and the GIS maps. The analysis of the conservative value allowed interpreting and classifying, in São Gabriel, the areas in accordance with a gradient of conservative value. It was also possible to evaluate the distribution of taxonomic groups and species that contributed to the formation of the map of the conservative value this information is a subsidy for the development of land management strategies as the Biodiversity Management concepts.
\end{abstract}

Keywords: Conservative value. Conservation of habitat. Biodiversity. 


\section{Introdução}

As mais recentes estimativas da diversidade de espécies no planeta apontam a existência de 10 milhões de formas de vida, das quais apenas cerca de 1,7 milhões já estariam classificadas (IUCN, 2014). Segundo a International Union for Conservation of Nature (IUCN), no ano de 2014, 11.167 espécies corriam o risco de desaparecerem do planeta. Entre eles estavam 5.453 espécies da fauna e 5.714 espécies de plantas (IUCN, 2014).

O Brasil é responsável pela gestão do maior patrimônio de biodiversidade do mundo: são mais de 100 mil espécies de invertebrados e aproximadamente 8.200 espécies de vertebrados (713 mamíferos, 1.826 aves, 721 répteis, 875 anfíbios, 2.800 peixes continentais e 1.300 peixes marinhos), das quais 627 espécies estão listadas como ameaçadas de extinção, sendo uma obrigação do poder público e da sociedade protegê-las (ICMBIO, 2014).

Desta forma, deve-se levar em consideração a ação humana nos processos dinâmicos do ambiente natural, para obter uma visão dos componentes natural e social na composição de decisões futuras (GOTELLI, 2004).

O ser humano inicia sua relação com a natureza a partir do momento da ocupação e utilização do ambiente natural, ou seja, das ações da sociedade sobre os sistemas físicos naturais.

A partir desta relação, processos morfo-dinâmicos se iniciam alterando as propriedades originais do ambiente e, quando intensificados, podem ocasionar riscos ambientais, tornando mais ou menos frágil um ambiente (REIS, 2012). Sendo assim, ocorre uma relação intrínseca entre as fragilidades ambientais, a ecologia da paisagem e o uso da terra.

De acordo com os dados, qual seriam as estratégias mais eficientes para a gestão e conservação da biodiversidade?

\section{Metodologia}

O Município de São Gabriel está situado na região da Campanha e possui a população de 62.594 habitantes e área territorial de $5.023,821 \mathrm{Km}^{2}$. De acordo com as coordenadas geográficas (Latitude 30 20' 27" Sul e Longitude 54 19’ 01" Oeste), o município de São Gabriel está localizado na metade sul do Estado do Rio Grande do Sul, com a distância de $320 \mathrm{~km}$ a oeste da capital Porto Alegre (IBGE, 2014), conforme Figura 1.

O levantamento das espécies da fauna silvestre foi realizado com o recorte das espécies ameaçadas de extinção nos mapas de distribuição geográfica do Livro Vermelho da Fauna Ameaçada de Extinção no Rio Grande do Sul (FONTANA; BENCKE; REIS, 2003) e no Livro de Mamíferos do Rio Grande do Sul (WEBER; ROMAN; CÁCERES, 2013).

A seleção das espécies foi realizada com o auxílio de uma lâmina transparência para assinalar os limites

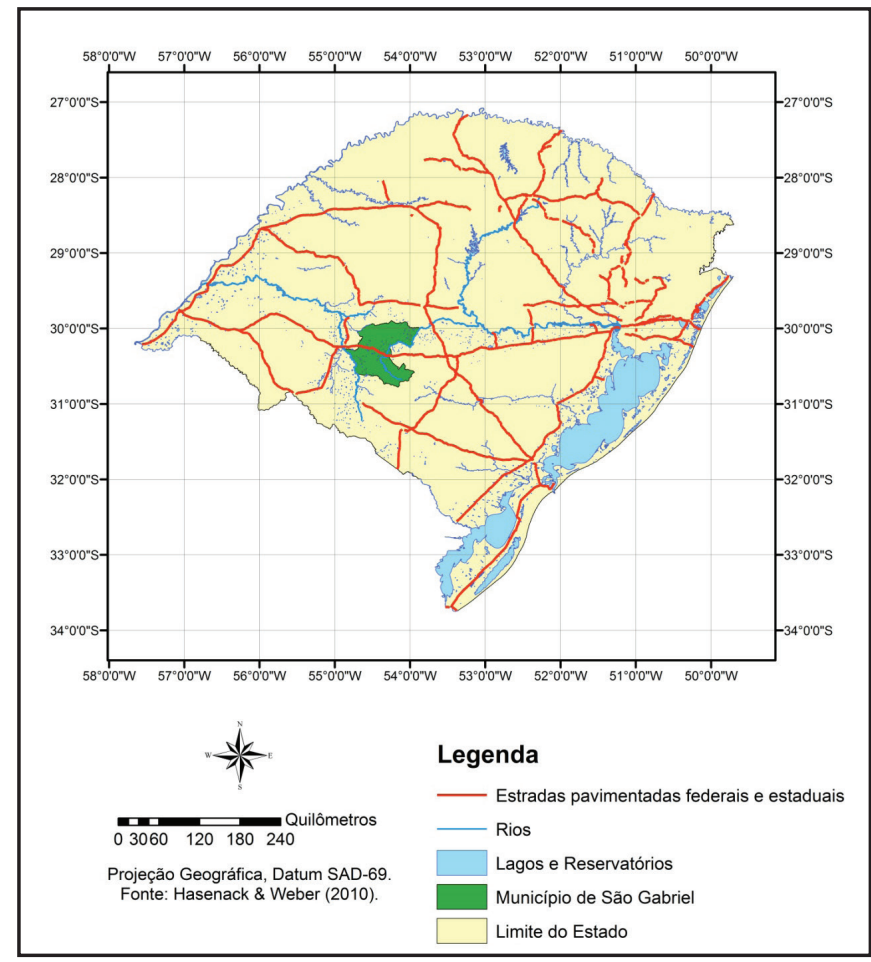

Figura 1: Mapa de situação e localização do Município de São Gabriel, RS, Brasil

geográficos do município de São Gabriel, considerando uma abordagem em nível de bacias hidrográficas: Rio Camaquã, Rio Santa Maria e Rio Vacacaí - Vacacaí - mirim.

Também foram consultadas as informações dos critérios de seleção para delimitar o hábitat potencial de cada espécie, entre elas, o nome científico e vulgar, status de conservação, endemismo, vegetação, altimetria e proximidade de corpos d'água, como pode ser visto na Tabela 1.

Tabela 1: Critérios de seleção das espécies da fauna silvestre ameaçada de extinção

\begin{tabular}{c|c}
\hline \multicolumn{2}{c}{ Critérios de Seleção } \\
\hline Espécies & Vegetação \\
Ameaçadas de & Altitude \\
Extinção: Status de & Proximidade de \\
Conservação e & corpos d'água \\
Endemismo &
\end{tabular}

O parâmetro para avaliação dos mapas foi a escala de fragilidades, onde em cada um dos hábitats potenciais da fauna silvestre é atribuída uma nota de fragilidade que é composta através da relação entre o status de conservação e o tipo de espécie (endêmica ou não).

A escala de fragilidade varia em uma escala entre 1 a 255 e está sinalizada nas cores que variam, respectivamente, entre as cores em vermelho ao verde. As áreas em vermelho são às de maior valor conservativo e assumem um valor de até 255 (duzentos e cinquenta e cinco). As 
Tabela 2: Valores de Fragilidade (1: muito baixa; 255: muito alta) para o mapa do valor conservativo do hábitat das espécies da fauna silvestre.

\begin{tabular}{c|c|c|c}
\hline Status de Conservação & $\begin{array}{c}\text { Não } \\
\text { endêmica }\end{array}$ & $\begin{array}{c}\text { Endêmica da Unidade } \\
\text { da Federação ou do Bioma }\end{array}$ & $\begin{array}{c}\text { Endêmica do Alto } \\
\text { e Médio Uruguai }\end{array}$ \\
\hline Criticamente em & 26 & 128 & 254 \\
Eerigo/Provavelmente Extinta & 18 & 89 & 179 \\
Vulnerável & 5 & 26 & 51 \\
\hline
\end{tabular}

áreas em verdes são às de menor valor conservativo e assumem o valor de no mínimo 1 (um).

Através da relação entre o status de conservação e o tipo de espécie foi possível atribuir uma nota ao mapa do valor conservativo do hábitat potencial de cada espécie da fauna silvestre, conforme Tabela 2 .

O processamento dos mapas foi realizado no programa ARCGIS, versão 9.3., onde foram processados os mapas do valor conservativo do hábitat potencial de cada espécie da fauna silvestre, do valor conservativo do hábitat potencial dos grupos taxonômicos e o do valor conservativo dos hábitats potenciais da fauna silvestre para o Município de São Gabriel, RS.

Para o processamento do mapa do valor conservativo do hábitat potencial de cada espécie da fauna silvestre foi necessário utilizar mapas de base com o devido recorte das informações de vegetação, altimetria e proximidade de corpos d'água. Os mapas de base foram obtidos do MMA (2007), INPE (2008) e Hasenack \& Weber (2010).

As informações altimétricas foram obtidas a partir do modelo numérico de terreno através de um fatiamento obtido por reclassificação, atribuindo-se 1 a todos os pixeis que estavam incluídos nos intervalos de altitude definidos na descrição do hábitat e zero para os demais.

O componente vegetacional do hábitat potencial foi obtido a partir de uma operação de seleção das categorias de vegetação incluídas na descrição do hábitat potencial da espécie, com base no mapa da cobertura vegetal do Bioma Pampa, seguida da exportação da seleção para um novo arquivo vetorial. Este arquivo foi rasterizado e reclassificado, para que as áreas incluídas no hábitat potencial recebessem o valor 1 e as demais valor zero.

A informação referente à proximidade dos corpos de água foi definida através da obtenção de um buffer de 100 metros no entorno dos corpos de água, representados pela drenagem (linhas) e pelos polígonos representando os rios de grande porte, lagos e açudes. Foi atribuído valor 1 para os polígonos resultantes da operação e zero para a área externa aos mesmos. Posteriormente, foram rasterizados.
O mapa do hábitat potencial para a espécie foi obtido através da identificação da intersecção dos três critérios, obtida através de uma combinação de uma operação de soma de mapas seguida de uma operação de reclassificação. Se estivessem presentes os três critérios, o valor máximo da soma ocorreria onde os três componentes do hábitat estivessem presentes, ou seja, seriam os pixeis com valor de 3 . Através da reclassificação, todos os pixeis com valor 3 seriam reclassificados para o valor da espécie (considerando status de conservação e endemismo).

A valoração dos polígonos dos hábitats potenciais foi realizada com a atribuição de notas conforme o status de conservação das espécies ameaçadas de extinção (Tabela 2). Este procedimento foi efetuado através de operação de reclassificação no ARCGIS. Na sequência, os mapas com os polígonos valorados de cada espécie foram somados, utilizando-se a calculadora de mapas do ARCGIS, resultando em um mapa que apresenta o valor conservativo.

O mapa do valor conservativo foi obtido para todo o conjunto das espécies ameaçadas, como, também, para os diferentes grupos taxonômicos.

\section{Resultados e Discussões}

A análise do mapa do valor conservativo permitiu a interpretação das regiões com o maior e o menor valor conservativo, assim como, a visualização das regiões com o valor conservativo intermediário.

Também foi possível avaliar a distribuição dos grupos taxonômicos nestas regiões e as espécies que contribuíram para a formação do mapa do valor conservativo dos hábitats potenciais da fauna silvestre.

O mapa do valor conservativo é um subsídio para o desenvolvimento de estratégias de gestão territorial conforme os conceitos de Gestão da Biodiversidade.

Através da interpretação do mapa do valor conservativo dos hábitats potenciais da fauna silvestre (Figura 2), pode-se classificar o território do município de São 


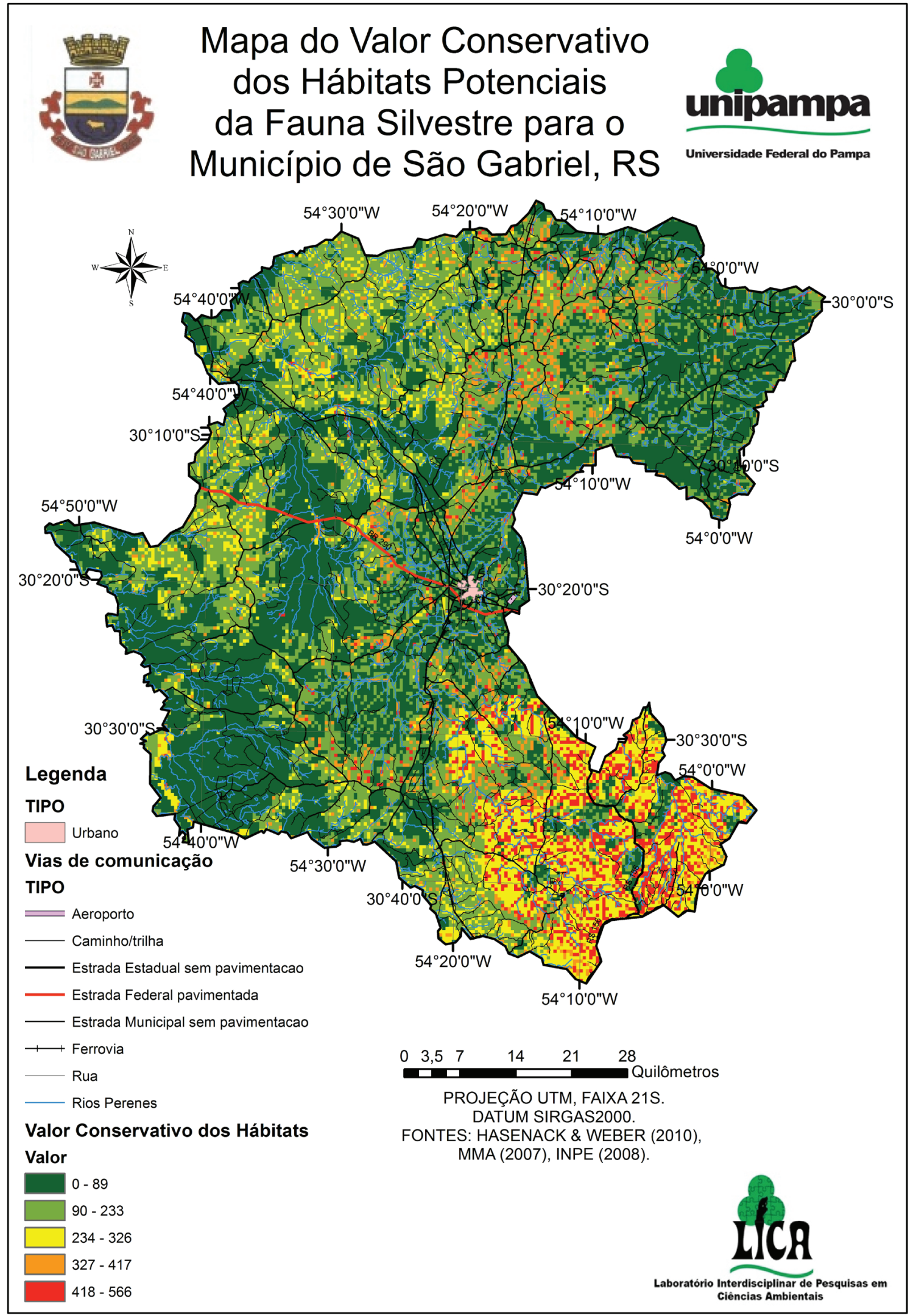

Figura 2: Mapa do valor conservativo dos hábitats potenciais da fauna silvestre para o município de São Gabriel, RS, Brasil. 
Gabriel em três regiões distintas com alto, médio e baixo valor conservativo.

O local com maior valor conservativo é a região assinalada em vermelho (que está situada ao sul do município de São Gabriel), que compreende parte da Bacia Hidrográfica dos rios Vacacaí-Vacacaí-Mirim, os campos e florestas da região sul e parte da Serra do Sudeste. Esta região é a principal área para o desenvolvimento de um estudo de viabilidade para implantação de uma Unidade de Conservação. Os fatos que fazem desta área aquela com maior valor conservativo estão relacionados com a presença de espécies da fauna silvestre com status de conservação em perigo, criticamente em perigo ou provavelmente extinta, assim como, a presença da maior parte de espécies endêmicas.

Outra área com valor conservativo entre médio e alto são àquelas que apresentam a coloração em amarelo ou amarelo com traços em vermelho. Estas regiões situam-se ao norte do município de São Gabriel, que compreendem a vegetação de campos, banhados e florestas. Pode-se verificar, no mapa, que a região citada está associada com a Depressão Central, a Bacia Hidrográfica do Rio Santa Maria e a Bacia Hidrográfica dos Rios VacacaíVacacaí-Mirim. As áreas com a coloração em amarelo e amarelo com traços em vermelho apresentam potencial para uma área de corredores ecológicos, para dispersão e reprodução de diversas espécies.

Já as áreas em verde são aquelas que apresentaram o menor valor conservativo. A região assinalada em verde está associada com a presença de muitas espécies com status de conservação preocupação menor e vulnerável, que, na sobreposição dos mapas, resultam em um baixo valor conservativo (Figura 2 ).

\subsection{Espécies em destaque}

Através da consulta no Livro Vermelho da Fauna Ameaçada do Estado do Rio Grande do Sul (FONTANA; BENCKE; REIS, 2003) e Livro dos Mamíferos do Rio Grande do Sul (WEBER; ROMAN; CÁCERES, 2013), pode-se citar entre as espécies levantadas na área de abrangência deste trabalho a existência de uma espécie com status de conservação provavelmente extinta, três espécies criticamente em perigo, onze espécies em perigo, quarenta e uma espécies vulneráreis e trinta e nove espécies com preocupação menor. Outras cinco espécies tem o status de conservação com dados insuficientes.

As espécies que mais contribuíram com o valor conservativo na área em vermelho, que engloba parte da Bacia Hidrográfica dos Rios Vacacaí-Vacacaí-Mirim, parte da Serra do Sudeste e campos e florestas ao sul do município de São Gabriel estão destacadas como seguem.

Entre as espécies do grupo dos Moluscos pode-se citar a Diplodon koseritzi (Marisco-do-junco) que é uma espécie do tipo endêmica e com o seu status de conservação em perigo e a Leila blainviliana (Leila) que apresenta o status de conservação em perigo.

No grupo dos Himenópteros, a Plebeia wittmanni (Abelha-mirim) e a Bicolletes pampeana, ambas endêmicas e com o status de conservação em perigo. Também a Bicolletes franki que tem o status de conservação em perigo.

Entre as espécies do grupo dos Peixes é possível citar as espécies Austrolebias cyaneus, Austrolebias ibicuienses e Astrolebias periodicus (todos conhecidos como peixes-anuais) que são peixes com ciclo de vida anual e tem o seu hábitat relacionado com as regiões de banhados e várzeas. A principal ameaça é a redução do hábitat pela drenagem de banhados e várzeas para o cultivo agrícola (COSTA, 2002; FONTANA; BENCKE; REIS, 2003). O status de conservação destas espécies é respectivamente, em perigo, criticamente em perigo e vulnerável. Outra informação importante é que ambas são espécies endêmicas da região do pampa gaúcho.

No grupo das Aves é possível citar as espécies Sarcoramphus papa (Urubu-rei), Cairina moschata (Pato-do -mato), Anodorhynchus glaucus (Arara-azul-pequena) e o Cistothorus platensis (Corruíra-do-campo) que tem o status de conservação, respectivamente, criticamente em perigo, em perigo, regionalmente extinta e em perigo.

Entre o grupo dos Carnívoros estão relacionadas às espécies Chrysocyon brachyurus (Lobo-guará) e a Oncifelis colocolo (Gato-palheiro), com o status de conservação, respectivamente, criticamente em perigo e em perigo.

No grupo dos Ungulados pode-se citar somente a Mazama americana (Veado-pardo) que tem o seu status em perigo.

No grupo dos Roedores também está em destaque a Agouti paca (Paca) com o status de conservação em perigo. Na região assinalada nas cores em amarelo e nas regiões em amarelo com traços em vermelho predominou a presença de espécies com status de conservação entre preocupação menor e vulnerável. Também em menor proporção as espécies com status de conservação em perigo ou criticamente em perigo.

A espécie do grupo dos Moluscos que contribuiu para o valor conservativo intermediário está relacionada com a espécie endêmica Leila blainviliana (Leila) que tem o status de conservação em perigo.

No grupo dos Peixes as espécies que possuem o hábitat nas regiões em amarelo são o Austrolebias cyaneus, Austrolebias ibicuienses e Austrolebias periodicus que são espécies endêmicas com status de conservação, respectivamente, em perigo, criticamente em perigo e vulnerável.

No grupo das Aves, ocorre a presença das espécies Sarcoramphus papa (Urubu-rei) e Cairina moschata (Patodo-mato), que têm o status de conservação, respectivamente, criticamente em perigo e em perigo.

Algumas espécies do grupo dos carnívoros também estão associadas à região em amarelo como o Chrysocyon brachyurus (Lobo-guará) e a Oncifelis colocolo (Gato-palheiro). 


\subsection{Estratégias de gestão da biodiversidade}

Conforme Fontana, Bencke e Reis (2003), as principais ameaças estão relacionadas com a perda da estabilidade dos ecossistemas provocados pela destruição, descaracterização e degradação do hábitat, redução do hábitat, efeitos de barragens, queimadas, remoção de indivíduos da natureza, atropelamentos, comércio e caça ilegal, pesca predatória, efeitos de poluentes, introdução de espécies exóticas, hibridação e agentes patogênicos.

Segundo o mesmo autor, as principais ações recomendadas são a recuperação e proteção do hábitat, os estudos sobre a biologia das espécies, a criação de unidades de conservação, o desenvolvimento de programas de Educação Ambiental e a fiscalização contínua e permanente.

Nos locais assinalados em vermelho, a estratégia de conservação envolve a criação de uma Unidade de Conservação, recuperação e proteção dos hábitats, inventário e monitoramento da fauna, programas de educação ambiental e fiscalização.

Nas áreas particulares é possível desenvolver programas para a criação de unidades de conservação de uso sustentável na categoria de Reserva Particular do Patrimônio Natural (RPPN).

\section{Conclusões}

O Mapa do Valor Conservativo dos Hábitats Potenciais da Fauna Silvestre no Município de São Gabriel permitiu identificar as áreas de maior valor conservativo, às de valor intermediário e as áreas de menor valor conservativo.

A identificação das áreas de maior valor potencial poderá subsidiar processos de tomada de decisão para a conservação da biodiversidade, orientando esforços para inventariamento, monitoramento, fiscalização e ações de educação ambiental no Município de São Gabriel, RS.

Também poderá servir como informação para subsidiar ações de planejamento do uso da terra e para análise de impactos ambientais, com uso potencial nos instrumentos de planejamento e gestão ambiental e de recursos hídricos.

A região do município que apresenta o maior potencial para ocorrência de espécies ameaçadas de extinção está situada no sul do município, na parte da Serra de Sudeste.

Na região assinalada ao norte, em cor amarela e amarela mesclada com vermelho, existe a necessidade de aprofundar o conhecimento sobre a biodiversidade, uma vez que existe uma concentração de fragmentos de alto valor mesclados com fragmentos de valor intermediário, que podem estar, ainda, conectados.

Nas demais áreas, embora os valores potenciais dos hábitats sejam baixos, a existência de corredores deve ser investigada, principalmente aqueles que seguem as drenagens e que tem potencial de conectar as duas regiões de mais alto valor conservativo, no sul e norte do município.

\section{Referências}

COSTA, W. J. E. M. Peixes anuais brasileiros: diversidade e conservação. Curitiba, PR: Ed. UFPR, 2002. 238pp.

FONTANA, C. S.; BENCKE, G. A.; FONTANA, C. S.; REIS, R. E. Livro Vermelho da Fauna Ameaçada de Extinção no Rio Grande do Sul. Porto Alegre, RS: Ed. Edipucrs, 2003, 632p.

GOTELLI, N. J. Ecologia. Londrina, PR: Ed. Planta, 2007, 260p.

HASENACK, H.; WEBER, E. (org.) Base cartográfica vetorial continua do Rio Grande do Sul - Escala 1:50.000. Porto Alegre, UFRGS - IB - Centro de Ecologia. 2010. 1 DVD-ROM (Série Geoprocessamento, 3).

IBGE, Instituto Brasileiro de Geografia e Estatística: Município de São Gabriel. Disponível em http://www. ibge.gov.br/ Acesso em: 10/01/2014.

ICMBIO, Instituto Chico Mendes de Conservação da Biodiversidade. Disponível em: http://www.icmbio.gov. br/portal/ Acesso em: 10/01/2014.

INPE. Instituto Nacional de Pesquisas Espaciais. 2008 TOPODATA: Banco de Dados Geomorfométricos do Brasil. Disponível em: http://www.dsr.inpe.br/topodata/ Acesso em: $28 / 10 / 2008$.

IUCN, União Internacional para a Conservação da Natureza e dos Recursos Naturais. Lista Vermelha de Espécies Ameaçadas de Extinção. Disponível em: http:// www.iucnredlist.org Acesso em: 10/01/2014.

MMA. Ministério do Meio Ambiente. 2007. Cartas de vegetação PROBIO (MMA). Brasília: PROBIO/MMA, 2007. (mapa digital). Disponível em: http://mapas.mma.gov.br/ mapas/aplic/probio/datadownload.htm?//pampa/index. html, acesso em 05/05/2008.

REIS, J. T. Análise de fragilidade ambiental em bacia hidrográfica urbana para subsidiar uma avaliação integrada. Tese de doutorado, Instituto de pesquisas hidráulicas, Universidade Federal do Rio Grande do Sul, 2012, 213p.

WEBER, M. M.; ROMAN, C.; CÁCERES, N. C. Mamíferos do Rio Grande do Sul. Santa Maria, RS: Ed. UFSM, 2013, $556 \mathrm{p}$. 